\title{
Design of Intelligent Robot as a Tool for Teaching Media Based on Computer Interactive Learning and Computer Assisted Learning to Improve the Skill of Learner
}

\author{
M. Syariffuddien Zuhrie \\ Universitas Negeri Surabaya \\ Kota Surabaya, Indonesia \\ e-mail: zuhrie@unesa.ac.id \\ Nur Kholis \\ Universitas Negeri Surabaya \\ Kota Surabaya, Indonesia
}

\author{
Achmad Imam Agung \\ Universitas Negeri Surabaya \\ Kota Surabaya, Indonesia \\ Subuh Isnur Haryudo \\ Universitas Negeri Surabaya \\ Kota Surabaya, Indonesia
}

\begin{abstract}
The development of robotics in Indonesia has been very encouraging. The barometer is the success of the Indonesian Robot Contest (Kontes Robot Indonesia). In the contest no less than 40 major universities in Indonesia took part. The focus of research in the first year is a teaching module manufacturing, planning mechanical design, control system through microprocessor technology and maneuverability of the robot. Computer interactive computer and computer assisted learning strategies is a teaching strategy that emphasizes the use or the use of computers and learning aids (assisted learning) in teaching and learning activity. this research the development model used is the 4-D model. This model suggested by Thiagarajan, Semmel, and Semmel (1974). 4-D Model consists of four stages: Define Stage, Design Stage, Develop Stage, and Disseminate Stage. This research was conducted by applying the research design development with the aim to produce a tool of learning in the form of intelligent robot modules and kit based on Computer Interactive Learning and Computer Assisted Learning at the Department of Electrical Engineering to improve the skills of learners. From the data of the Indonesia Robot Contest during the period 2009-2015 can be seen that the modules that have been developed have reached the fourth stage of the research methods of development that disseminate methods. So that, the module is perfect, ready to be duplicated and distributed as learning devices subject of intelligent robot courses. Socialization questionnaires showed that levels of student majoring in electrical engineering competencies image currently only limited to conventional machines. The average assessment is 3.34 validator included in either category. Modules developed can give hope to the future are able to produce Intelligent Robot Tool for Teaching Based on Computer Interactive Learning and Computer Assisted Learning to improve the skills of learners that can be applied to the field. Results of student responses also showed a positive response to the module of robotics and computer-based interactive learning assisted learning developed. The average assessment is 3.34 validator included in either category.
\end{abstract}

Keywords-Intelligent Robotics Learning Tool, Computer Interactive Learning, Computer Assisted Learning, Course of Intelligent Robotics, The Indonesia Robot Contest

\section{INTRODUCTION}

The development of robotics in Indonesia has been very encouraging. The barometer is the success of the Indonesian Robot Contest (Kontes Robot Indonesia). In the contest no less than 40 major universities in Indonesia took part. But the development of such robots is limited to the contest and has not been developed to address the issues more real, especially in the industrial world.

The focus of this research is the design of the device in the course of intelligent robotics through the fire fighter home robot that is booming and will be implemented in annual of the Indonesia Robot Contest and the industrial in order to advance the world of robotics Indonesia. Robots of this type developed by developed countries such as America, Japan, the United Kingdom the cost is very high. Currently the robot actually uses high tech, because the control is fully controlled by a microprocessor as a substitute for human and we strive to develop the Low Cost Technology. [1]

The focus of research in the first year is a teaching module manufacturing, planning mechanical design, control system through microprocessor technology and maneuverability of the robot. The first year of the study is expected to produce an intelligent robot that is reliable both in terms of technology and in terms of economy.

The principal issue is how the curriculum and the learning modules are implemented in accordance with the approach of industrial needs. [2] In order to support competency-based curriculum needs of the industry, has also 
been compiled modules both manual and interactive, oriented to the achievement of competence as well as accommodate the working life skills. With regard to the problems that will arise is what kind of learning modules appropriate to the characteristics of the attainment of the goal of learning the world of work as well as the achievement of competence in the field of life skills by using the main teaching materials in the form of modules and learning media. [3]

To answer these problems in this study will be compiled in the form of learning devices in the course of intelligent robot tool for teaching based on computer interactive learning and computer assisted learning to the needs of industry. Expected results of this study will be able to bridge the needs of energy, particularly of graduates majoring in Electrical Engineering the State University of Surabaya which will work as a vocational teacher or plunge into the world of industry.

\section{THEORETICAL FRAMEWORK}

Computer Interactive Learning And Computer Assisted Learning Strategy

Computer interactive computer and computer assisted learning strategies is a teaching strategy that emphasizes the use or the use of computers and learning aids (assisted learning) in teaching and learning activity. The use of computers as a learning medium useful for learners to simulate the material learned. [4] The simulation results of these computers will be applied, or applied to the learning tools (assisted learning) that exist. [5] So through interactive learning strategies and computer assisted learning easier for students to understand the material and apply the concept of the material on teaching aids directly.

To support the teaching and learning process and assisted interactive computer-based learning, the necessary infrastructure in the form of learning equipment consisting of:

a) Computer interactive learning is a computer device containing computer programs (software) that can be used to perform simulations of materials studied by learners. Examples of simulation programs for learning Computer Interactive Learning. ${ }^{[23]}$

b) Computer Assisted Learning is a learning tool that can be used to apply the results of computer simulation on the appliance directly. ${ }^{[12]}$

\section{Development Learning Tool 4-D Model}

In this research the development model used is the 4-D model. This model suggested by Thiagarajan, Semmel, and Semmel (1974). [6] 4-D Model consists of four stages:

\section{Define Stage}

The purpose of this stage is to determine and define the conditions of learning. This phase has five basic steps include: front-end analysis, learner analysis, concept analysis, task analysis, and formulation of learning objectives. ${ }^{[14]}$

\section{Design Stage}

The design of prototype learning device is produced. Result of this phase is usually a preliminary design of the learning device depending on requirements. Device components used are very diverse, such as: student book, modules, teacher guide, student activity sheets, lesson plans, tests of student learning outcomes, and learning media. ${ }^{[14]}$

\section{Develop Stage}

This stage aims to produce learning tools that have been revised based on the input of experts. The next step is a trial with an appropriate number of students in a class of real (not unlimited). This activity was conducted to determine how effective learning tools developed when applied to the learning process. The effectiveness of the learning device can be seen through the observation, for example, the activities of teachers and students, the ability to manage learning and student achievement test.

Disseminate Stage

At this stage is the stage of deployment and use learning device. Learning tools that have been tested and revised earlier, duplicated and distributed for use on learning in a larger scale. ${ }^{[14]}$

III. Research Methods

This research was conducted by applying the research design development with the aim to produce a tool of learning in the form of intelligent robot modules and kit based on Computer Interactive Learning and Computer Assisted Learning at the Department of Electrical Engineering to improve the skills of learners ${ }^{[20]}$

\section{Development Procedures}

Procedure development in research carried out through several stages as follows:

a. Identifying the various issues surrounding the intelligent robot used in contests robot through the study of literature and data mining to be used as reference for the formulation of theory, simulation and applications approach;

b. Analyze and formulate the identification of various issues surrounding the intelligent robot relevant to developed in the Department of Electrical Engineering Analyze and formulate the identification of various issues surrounding the intelligent robot relevant to developed in the Department of Electrical Engineering;

c. Make analysis and draw up scenarios Content and Design of Learning and infrastructure needed for the development of equipment, teaching staff, laboratory personnel, and the establishment of appropriate evaluation system material needs robotics;

d. Formulate indicators of success for teaching and learning process oriented to the achievement of the performance demands of the professional needs; 


\section{PRESS}

e. Implementation of the manufacture of teaching modules and learning devices (kit) based on Computer Interactive Learning and Computer Assisted Learning as a means to integrate the theory, simulations and applications suitable with various issues surrounding the learning needs and intelligent robot for contest;

f. Conduct field trials on intelligent robot course tools of learning based on Computer Interactive Learning and Computer Assisted Learning in the Department of Electrical Engineering oriented to the mastery of the competency needs;

g. Analyzing the results of field trials and make improvements to validate test procedures and test results;

h. Doing the final revision of the intelligent robot course tools of learning based on Computer Interactive Learning, Computer Assisted Learning, the results of field test and validation. ${ }^{[20]}$

\section{Data Collection and Analysis Techniques Data}

Information on the results of field surveys and discussions in order to implement the standards needs of the Indonesia Robot Contest and the learning device is analyzed with descriptive techniques. Likewise, data from focus group discussions in order to identify and formulate the essential topics as teaching materials for integrated mechatronic courses in the form of theory, simulation, and applications by using qualitative descriptive analysis techniques. Qualitative descriptive analysis techniques emphasis on making the evaluation and synthesis of the conclusions result from the activities. Synthesis and conclusions on the outcome of this study was formulated through forums workshops and focus group discussions. ${ }^{[26]}$

\section{RESULTS AND DISCUSSION}

1. Data from the Indonesia Robot Contest 2009-2015

From the data of the Indonesia Robot Contest during the period 2009-2015 can be seen that the modules that have been developed have reached the fourth stage of the research methods of development that disseminate methods. So that, the module is perfect, ready to be duplicated and distributed as learning devices subject of intelligent robot courses. In Indonesia Robot Contest, material-based teaching module compiled specifically for the contest is not only electrical or electronic engineering majors alone, but multi-disciplines, and the object of research being developed not to be the latest technology and appropriate technology alone, but include the development of learning tools.

2. Data Socialization Result in Student Learning Tool

Based on the data about the socialization of the learning is done on students majoring in electrical engineering at the above resulted in the following data. For questions 1, 2, and 3 all respondents consisting of 10 students from representatives of various courses in the department of electrical engineering (100\%) answered no understanding of the application of intelligent robot in the industry, or about intelligent robot equipment. Respondents also argued robotics competence that is not taught in the department of electrical engineering. This shows that the image of the competence of the department of electrical engineering is currently only limited to classic electronic circuit, which ranges on flip flop, NAND gate, AND gate only, not offensive competence in the industrial intelligent robot. Yet today the development of machinery industry has many uses industrial intelligent robot.

To question no. 4 of intelligent robot teaching module of computer-based interactive learning and assisted learning of respondents who answered draw was as much as 9 students $(90 \%)$ of the 10 student-vocational and vocational representatives argue unattractive as much as one student (10\%). As for the question no. 5 and no. 6 on the use of computer tools and modules of respondents who think "interesting" as many as 10 students (100\%) and argue "unattractive" as none (0\%). This shows the positive response of the device in the form of learning modules and devices are developed lesson

To question no. 7 all respondents as many as 10 people (100\%) found the module that was developed to facilitate the understanding of matter. All respondents (100\%) believed that they feel happy and motivated by learning to use teaching modules and tool of learning. This indicates that the module can be motivating learners and assist learners in understanding the material.

3. Data from the validation of learning by teaching staff (lecturers)

Module that has been created and then validated on 5 validator consisting of faculty learning experts, education experts, engineering experts and grammarians. And the average assessment is 3.34 validator included in either category. So that the module can be used in trial 2 that experiments performed in the course of intelligent robot.

\section{CONCLUSIONS}

Based on the results of data analysis and discussion, the researchers can draw conclusions as follows:

1. This is a module developed research results and monitoring research officer with the team for 6 years continues to develop research-based robotics contest, with the hope of the future be able to a tool of learning in the form of intelligent robot modules and kit based on Computer Interactive Learning and Computer Assisted Learning;

2. The results of student responses during learning tools developed socialization shows that the image of competence for the department of electrical 
engineering is currently still limited to classic electronic circuit, which ranges on flip flop, NAND gate, AND gate only, only, not offend industrial robots. Yet today the development of industrial automation has many uses industrial robots. Therefore we need a learning device that can support learning robotics competence in the department of electrical engineering. From the results of student responses also showed a positive response to the module of intelligent robot based on computer interactive learning and computer assisted learning developed.

3. Module that has been created and then validated on 5 validator consisting of faculty learning experts, education experts, engineering experts and grammarians. And the average assessment is 3.34 validator included in either category. So that the module can be used in trial 2 that experiments performed in the course of .

Based on the analysis of the data research and conclusions as well as the real conditions for research in the field, the researchers can provide advice as follows:

1. Keep the learning modules other than the subject of intelligent robot modules such as sensor module, the module microcontroller and others to support the course of mechatronic;

2. The method of computer interactive learning and computer assisted learning lectures should be done on any existing courses in addition to courses in intelligent robot. Because of lectures that use computers and assistive devices as a medium of learning can help improve the motivation of students to attend lectures and to facilitate students to understand the course materials;

3. Competence robotics needs to be taught in the department of electrical engineering, both for high school or university. Because intelligent robot competence is necessary for graduates majoring in engineering when it plunged into the world of industry, especially industries that the machines operate automatically.

\section{REFERENCES}

[1] Greinert, WD., 1992. The Dual System Of Vocational Training In The Federal Republic of Germany; Structure and function. Postfach 1, 61016326 Eschborn, Federal Republic of Germany

[2] Brown S. (1999) Reinventing the university. Assoc Learning Technol J; 6: 30-37. Fender B. The e-university project. London: Higher Education Funding Council for England.

[3] Adviso F, bernardo (1990). Development Of The National Training Council As The Coordinating Body For Technical And Vocational Trainng, Jakarta: Depdikbud

[4] Phillips R. 1996. Developers' guide to interactive multimedia. A methodology for educational applications. Perth: Curtin University Press,.

[5] Elves AW, Ahmed M, Abrams P. Computer-assisted learning; experience at the Bristol Urological Institute in the teaching of urology. Br J Urol 1997; 80 (suppl 3): 59-62

[6] Finch, Curtis R. \& john R Crunkilton. 1983. Curriculum Development in Vocational and Technical Education, London: Allyn and Bacon, Inc. 